\title{
INCIDENCE AND PROGRESS OF VESICOURETERIC REFLUX AFTER PRIMARY FULGURATION OF POSTERIORURETHRALVALVES
}

\author{
PERVEZ MMM ${ }^{1}$, HASINA K$^{2}, \mathrm{HUQ} \mathrm{MA}^{3}$.
}

\begin{abstract}
Introduction: Posterior urethral valve (PUV) is the most frequent cause of urethral obstruction in male child. These lesions usually result in lifelong disabilities with incontinence and decreased renal function despite optimal medical management. Primary fulguration without upper tract diversion is the preferred modality of treatment in most cases of PUV. Regular follow-up is needed to check completion of valve fulguration, renal function, status of hydronephrosis, vesicoureteric reflux (VUR), urinary tract infection (UTI), and bladder function.
\end{abstract}

Materials and methods: We conducted interventional study among 30 purposively selected patients of PUV in the Department of Pediatric surgery, Dhaka Medical College Hospital (DMCH), Dhaka, over a period of 20 months from December 2009 to July 2011. Age of study subjects varied from 2 days to 14 years. Among the 30 patients, 16 were children in the age group between 1year to14 years (53.3\%), $11(36.7 \%)$ were infants and the rest $03(10 \%)$ were neonates. Most of the patients presented with weak urinary stream, dribbling of urine, straining at micturition, UTI and palpable bladder. All children were subjected to ultrasonography (USG), blood urea, serum creatinine, routine urine examination and culture studies. Structured questionnaire was used to collect information regarding improvement or disappearance of VUR and renal functional status before \& after primary fulguration of PUV.

Results: Average serum creatinine level was found gradually decreased in subsequent follow up in comparison with the previous one. This difference of creatinine level was found

1. Dr. M.M. Masud Pervez, Assistant Professor, Department of Pediatric Surgery, BIRDEM General Hospital. Dhaka.

2. Dr.Kaniz Hasina, Associate Professor, Department of Pediatric Surgery, Dhaka Medical College \& Hospital, Dhaka.

3. .Dr.Md. Ashraf UI Huq, Professor \&Head, Department of Pediatric Surgery, Dhaka Medical College \& Hospital, Dhaka Correspondence to: Dr.M.M. Masud Pervez, Assistant Professor, Department of Pediatric Surgery, BIRDEM General Hospital. Dhaka. E-mail: shaheensb25@gmail.com statistically significant in t-test $(p<0.01)$. Average blood urea nitrogen (BUN) was also decreased which was found statistically significant $(p<0.05)$. VUR was present in $63.3 \%$ cases. Non- VUR was found in $60 \%$ cases on right side and $\mathbf{5 0 \%}$ cases on left side. On the third follow-up after 3 months it became $73.3 \%$ on right side and $63.3 \%$ on left side. Positive correlation found in Pearson correlation test about the changes of reflux grades before and after fulguration was significant at the level of $0.01(p<0.001)$. It was significant on both left and right kidneys. Positive correlation found in Pearson correlation test about the changes of GFR before and after fulguration was also significant at the level of $0.01(p<0.001)$. Collected data was cleaned, edited and analyzed with the help of software SPSS window version 15.0 .

Conclusion: In this study, VUR disappeared in some cases and decreased in majority of the cases by 3 months after adequate restoration of urethral patency. Renal function came to normal range in two thirds of the cases.

Key words: Posterior urethral valves (PUV) > Vesicoureteric reflux(VUR) $>$ Cystoscopic fulguration

\section{Introduction}

PUV comprises the most common congenital anomaly causing bladder outlet obstruction in boys. The incidence is between 1 in 5000 and 1 in 8000 male births $^{1,2}$. Langenbeck is credited with first reporting congenital obstruction of prostatic urethra in 1802. Despite this observation, it was left for Hough Hampton Young, more than a century later to define the condition and name it posterior urethral valves ${ }^{3}$. He described three types: type I, type II, type III urethral valves. Type I represents $95 \%$ of PUV. There is a membrane that originates at the verumontanum and travels distally to insert in the anterior proximal 
membranous urethra with an opening present posteriorly at the verumontanum. The etiology is probably a result of the mesonephric ducts entering the cloaca more anteriorly than normal and fusing in the midline ${ }^{4}$. Type II valves are now generally considered to be non obstructive and are of historical interest only. Type III valves represent the other $5 \%$ and consist of a ring-type membrane distal to the verumontanum with a perforation present centrally. The membrane may occasionally migrate distally, forming a windsock appearance ${ }^{5}$. The cause of these valves is an incomplete dissolution of the urogenital membrane. Primary fulguration without upper tract diversion is the preferred modality of treatment in most cases of PUV. Regular follow-up is needed to check completion of valve fulguration, renal function, status of hydronephrosis, VUR, UTI, and bladder function. Most of the available studies give widely variable data regarding the incidence of VUR, its course and correlation with renal function, with very few studies being available from the developing countries. In view of the above picture, this study will be conducted in the department of pediatric surgery, $\mathrm{DMCH}$.

\section{Materials and Methods}

Thirty children between the ages of 10 days and 14 years (median 19 months), seen over a period of 20 months were evaluated. PUV patients treated by fulguration alone were included. All children were subjected to USG, blood urea, serum creatinine, routine urine examination and culture studies. In presence of uremia, sepsis, dehydration, and metabolic derangements, preliminary catheterization was done until the above parameters improved and the child was fit for anesthesia and surgery. Whereas the blood urea and creatinine levels were done immediately after admission, the $99 \mathrm{mTc}$ dieethylene triamine pentaacetic acid (DTPA) scans were done electively after a period of catheterization followed by fulguration.PUV was confirmed on voiding cystourethrogram (VCUG) and at the same sitting, cystoscopy and fulguration of valves were done at 12, 2, 10, 5 and 7 o'clock positions using $7.5 \mathrm{Fr}$ resectoscope.VUR was graded according to the international grading system ${ }^{6}$. The urethral catheter retained for 12-24 $\mathrm{h}$ and in uncomplicated cases the child was discharged on oral antibiotic on the first postoperative day. In children with VUR, longterm uroprophylaxsis and periodic urine cultures were advised. Patients were followed up at 7 days, 1 month and 3 months, when renal function tests, USG, routine urine examination and culture, VCUG for VUR were carried out ${ }^{7}$. Glomerular filtration rate (GFR) was measured at presentation and after 3 months from the DTPA scan using Gates method ${ }^{8}$. Statistical analysis was performed using Pearson correlation test.

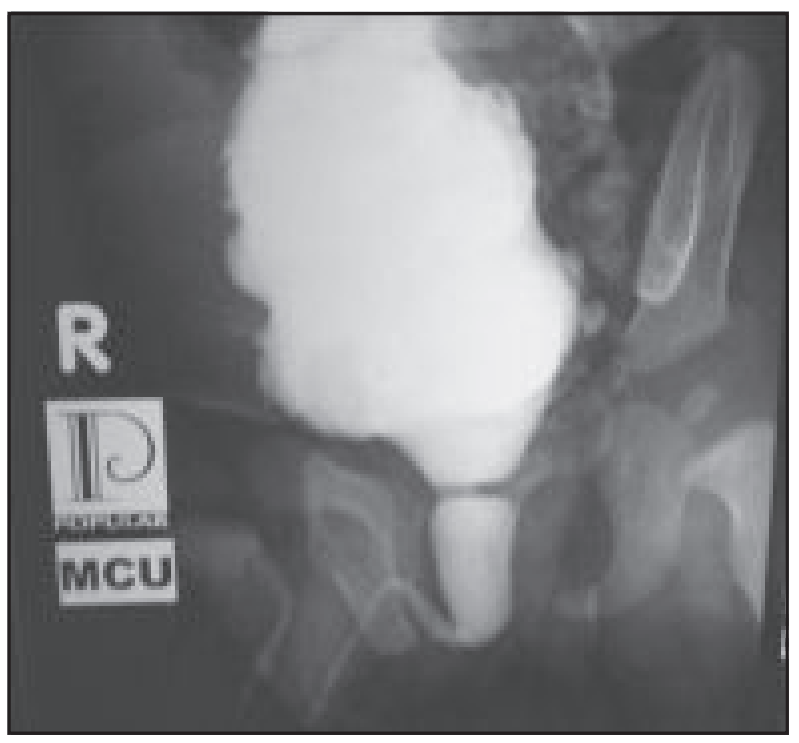

Fig.-1: VCUG shows PUV

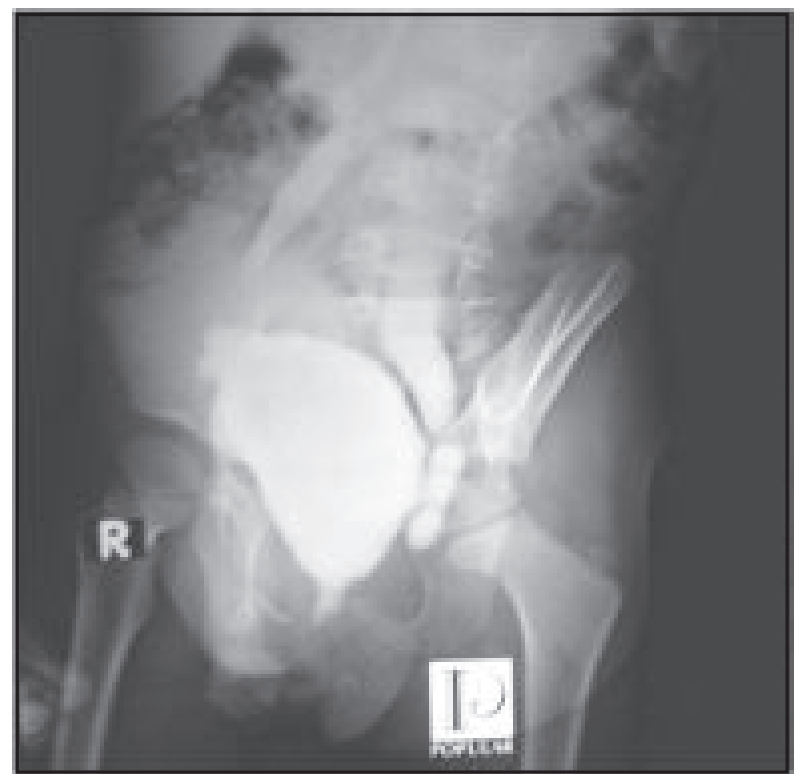

Fig.-2: Bilateral VUR 


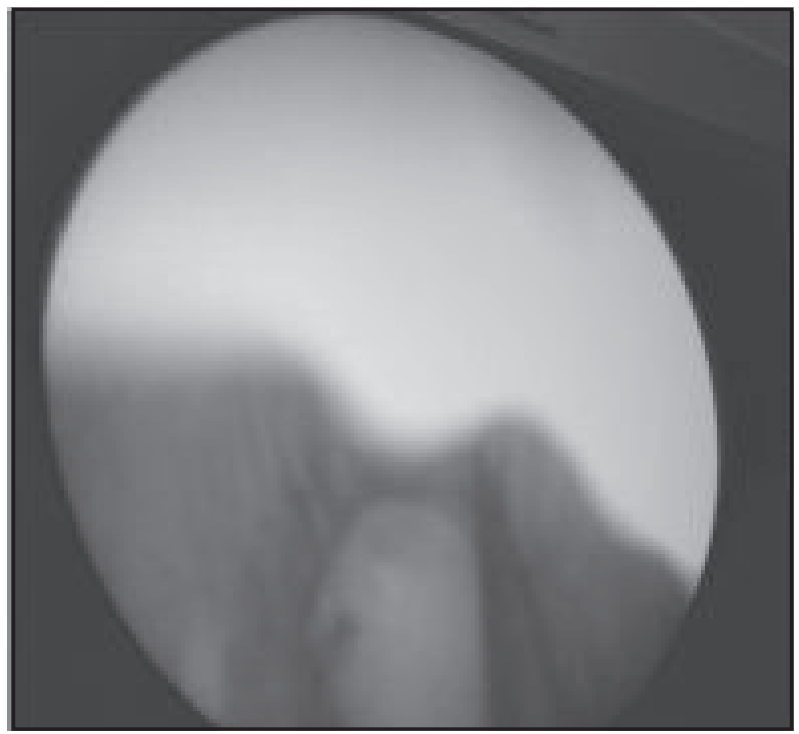

Fig.-3: Urethrocystoscopic view of PUV

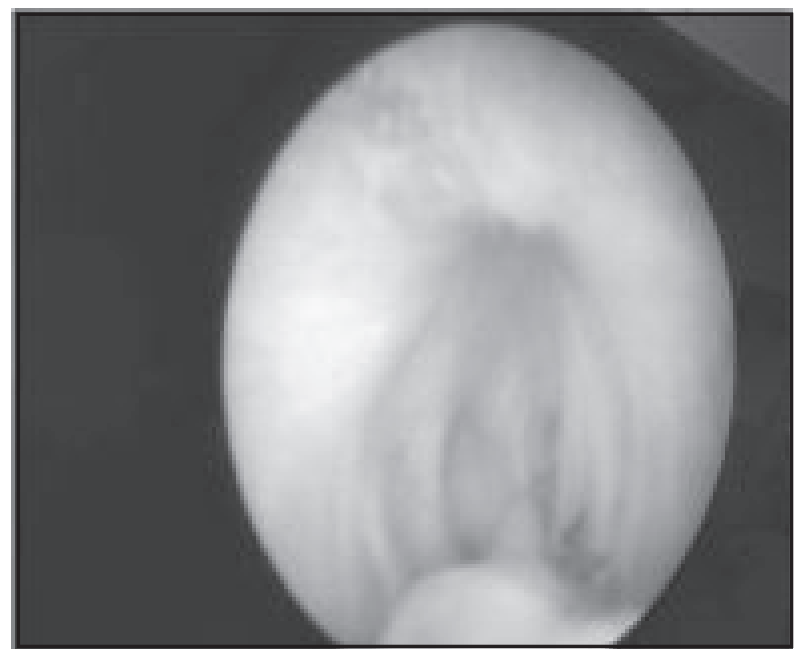

\section{Observation and Results}

An interventional study was carried out to determine the improvement of renal function and incidence and progress VUR occurring after primary fulguration of PUV in the Department of Pediatric surgery, $\mathrm{DMCH}$. A total 30 patients were selected according to selection criteria. Their parents were interviewed with a specific pre-designed and pre-tested questionnaire and other information was gathered by document review. Majority of the study subjects were children in between 1 to 5 years age group (43.3\%) and 5 to 14 years age group (10\%). 10\% were neonates between 2 days to 28 days age group and another $36.7 \%$ were infants between 1 month to 1 year age group. Among the study subjects more than two thirds of the subjects had weak urinary stream $(80.0 \%)$. Rest had normal urinary stream $(20.0 \%)$. Dribbling of urine was present among $76.7 \%$ subjects. Rest had no dribbling of urine (23.3\%).More than two thirds of the study subjects had straining at micturition (73.3\%), $26.7 \%$ had no such symptom. Half of the subjects had urinary tract infection (50.0\%). Most of the study subjects had no congenital anomaly $(96.7 \%)$, only $3.3 \%$ had congenital anomaly. After clinical examination only $6.7 \%$ kidneys were found ballotable. Rest was not ballotable on palpation. More than two thirds of the cases bladder was found palpable (73.3\%). Rest was not palpable (26.7\%). Phimosis was present in $20.0 \%$ cases, $80.0 \%$ cases had no phimosis.

Fig.-4: After fulguration of PUV

Table-I

Changes of serum creatinine level and BUN

\begin{tabular}{|c|c|c|c|c|c|}
\hline Biochemical Value(mg\%) & $\begin{array}{c}\text { On admission } \\
\text { Mean } \pm S D\end{array}$ & $\begin{array}{l}\text { After } 1 \text { Week } \\
\text { Mean } \pm S D\end{array}$ & $\begin{array}{l}\text { After } 1 \text { month } \\
\text { Mean } \pm S D\end{array}$ & $\begin{array}{l}\text { After 3months } \\
\text { Mean } \pm S D\end{array}$ & Pvalue \\
\hline Serumcreatinine & $1.03 \pm 0.45$ & $0.94 \pm 0.45$ & $0.82 \pm 0.43$ & $0.74 \pm 0.40$ & $<0.01$ \\
\hline BUN & $59.27 \pm 38.39$ & $51.0 \pm 34.13$ & $45.56 \pm 29.28$ & $43.1 \pm 25$ & $<0.05$ \\
\hline
\end{tabular}

Table-II

Progress of hydronephrosis following fulguration

\begin{tabular}{lcc}
\hline Grade of hydronephrosis & \multicolumn{2}{c}{ Number of renal units (proportion) } \\
\cline { 2 - 3 } & On admission & After three months \\
\hline 0 & $2(3.3)$ & $12(20.0)$ \\
I & $18(30.0)$ & $30(50.0)$ \\
II & $30(50.0)$ & $14(23.3)$ \\
III & $10(16.7)$ & $4(6.7)$ \\
Total & $60(100.0)$ & $60(100.0)$ \\
\hline
\end{tabular}


Average serum creatinine level was found gradually decreasing in subsequent follow up in comparison with the previous one. This difference of creatinine level was found statistically significant in t-test $(p<0.01)$. Average BUN also decreased which was found statistically significant $(p<0.05)$.

On admission hydronephrosis of different grades was found in $95.7 \%$ cases. Grade 0 hydronephrosis was found in $3.3 \%$ cases which became $20 \%$ after 3 months. Grade III hydronephrosis was found in $16.7 \%$ cases on admission which decreased after 3 months $(6.7 \%)$.

Among the study subject VUR was present $63.3 \%$. On admission non-VUR was found in $60 \%$ cases in right side and $50 \%$ cases in left side. On the third follow-up that is after 3 months it became $73.3 \%$ in right side and $63.3 \%$ in left side. On the other hand Grade V VUR was found in $13.3 \%$ cases on admission and $0 \%$ cases after 3 months in right side. There were $3.3 \%$ Grade V VUR on left side on admission and $0 \%$ cases 3 months after fulguration.

Table-III

Progress of VUR following fulguration

\begin{tabular}{lcccc}
\hline Grade of & \multicolumn{3}{c}{ VURNumber of renal units (proportion) } \\
& \multicolumn{2}{c}{ On admission } & \multicolumn{2}{c}{ After three months } \\
& Right & Left & Right & Left \\
\hline Non-VUR & $18(60.0)$ & $15(50.0)$ & $22(73.3)$ & $19(63.3)$ \\
I & $2(6.7)$ & $2(6.7)$ & $0(0)$ & $6(20.0)$ \\
II & $3(10)$ & $2(6.7)$ & $5(16.7)$ & $2(6.7)$ \\
III & $2(6.7)$ & $5(16.7)$ & $0(0)$ & $2(6.7)$ \\
N & $1(3.3)$ & $5(16.7)$ & $3(10.0)$ & $1(3.3)$ \\
V & $4(13.3)$ & $1(3.3)$ & $0(0)$ & $0(0)$ \\
\hline Total & 30 & 30 & 30 & 30 \\
& $(100.0)$ & $(100.0)$ & $(100.0)$ & $(100.0)$ \\
\hline
\end{tabular}

Positive correlation was found in Pearson correlation test about the changes of reflux grades before and after fulguration which was significant at the level of 0.01 . $(p<0.001)$. This correlation was significant in both left and right kidney.

Positive correlation was found in Pearson correlation test about the changes of GFR before and after fulguration which was significant at the level of 0.01 . (p $<0.001$ ).
Table-IV

Changes in reflux grades before and after fulguration

\begin{tabular}{|c|c|c|c|c|}
\hline \multirow[t]{2}{*}{ Age } & \multicolumn{2}{|c|}{ On admission } & \multicolumn{2}{|c|}{ After three months } \\
\hline & Left & Right & Left & Right \\
\hline \multicolumn{5}{|l|}{$\leq 1 / 12$} \\
\hline 10 days & 0 & 0 & 0 & 0 \\
\hline 10 days & 1 & II & 1 & II \\
\hline 15 days & 0 & 0 & 0 & 0 \\
\hline 30 days & IV & 0 & II & 0 \\
\hline \multicolumn{5}{|l|}{$1 / 12-1$ year } \\
\hline $1 \frac{1}{2}$ months & III & III & 1 & II \\
\hline 5 months & II & 1 & 0 & 0 \\
\hline 5 months & III & 1 & 1 & 0 \\
\hline 6 months & IV & 0 & IV & 0 \\
\hline 8 months & 0 & 0 & 0 & 0 \\
\hline 8 months & IV & 0 & III & 0 \\
\hline 9 months & 0 & 0 & 0 & 0 \\
\hline 9 months & IV & 0 & 0 & 0 \\
\hline 10 months & 0 & 0 & 0 & 0 \\
\hline 11 months & IV & II & II & 0 \\
\hline \multicolumn{5}{|l|}{$1-5$ years } \\
\hline 1 & 0 & 0 & 0 & 0 \\
\hline 1 & II & 0 & I & 0 \\
\hline 1 & III & 0 & I & 0 \\
\hline 2 & 0 & 0 & 0 & 0 \\
\hline 2 & 0 & 0 & 0 & 0 \\
\hline 2 & 0 & IV & 0 & II \\
\hline 2 & III & 0 & I & 0 \\
\hline $21 / 2$ & 0 & 0 & 0 & 0 \\
\hline 3 & 0 & 0 & 0 & 0 \\
\hline 3 & 0 & 0 & 0 & 0 \\
\hline 3 & 0 & II & 0 & 0 \\
\hline 3 & 0 & V & 0 & IV \\
\hline $41 / 2$ & III & V & 0 & IV \\
\hline \multicolumn{5}{|l|}{$5-10$ years } \\
\hline 5 & V & V & III & IV \\
\hline 5 & 0 & V & 0 & $\|$ \\
\hline $51 / 2$ & 1 & III & 0 & $\|$ \\
\hline
\end{tabular}


Table-V

Changes in GFR before and after fulguration

\begin{tabular}{|c|c|c|}
\hline Age & On admission & After 3 months \\
\hline \multicolumn{3}{|l|}{$\leq 1 / 12$} \\
\hline 10 days & 78 & 92 \\
\hline 10 days & 86 & 95 \\
\hline 15 days & 77 & 95 \\
\hline 30 days & 76 & 98 \\
\hline \multicolumn{3}{|l|}{$1 / 12-1$ year } \\
\hline $11 / 2$ months & 79 & 93 \\
\hline 5 months & 91 & 94 \\
\hline 5 months & 91 & 98 \\
\hline 6 months & 72 & 82 \\
\hline 8 months & 87 & 80 \\
\hline 8 months & 88 & 92 \\
\hline 9 months & 76 & 83 \\
\hline 9 months & 91 & 96 \\
\hline 10 months & 74 & 81 \\
\hline 11 months & 71 & 81 \\
\hline \multicolumn{3}{|l|}{$1-5$ years } \\
\hline 1 & 72 & 82 \\
\hline 1 & 75 & 87 \\
\hline 1 & 81 & 94 \\
\hline 2 & 64 & 82 \\
\hline 2 & 80 & 87 \\
\hline 2 & 84 & 89 \\
\hline 2 & 84 & 101 \\
\hline $21 / 2$ & 75 & 85 \\
\hline 3 & 80 & 85 \\
\hline 3 & 80 & 85 \\
\hline 3 & 96 & 95 \\
\hline 3 & 96 & 101 \\
\hline $41 / 2$ & 18 & 20 \\
\hline \multicolumn{3}{|l|}{$5-10$ years } \\
\hline 5 & 72 & 81 \\
\hline 5 & 72 & 60 \\
\hline $51 / 2$ & 133 & 134 \\
\hline
\end{tabular}

On admission $46.7 \%$ patients had found bacterial growth in culture of urine which became $10.0 \%$ after 1 month. After 3 months it was $13.3 \%$. On admission $53.3 \%$ patients had urinary tract infection which became $16.7 \%$ after 1 month. After 3 months it was $13.3 \%$.

\section{Discussion}

An interventional study was conducted to determine outcome of VUR after primary fulguration of PUVs among 30 diagnosed cases of PUVs at Department of Pediatric surgery, DMCH from December, 2009 to July, 2011.

Majority of the study subjects were children in the 1 to 14 years age group 16 (53.3\%).11(36.7\%) were infants 1 month to 1 year age group and another $03(10 \%)$ were neonates. Another study showed that a total of 181 boys with PUVs were age ranged from 2 days to 12 years. There were 53 (29.5\%) neonates (mean 12 days), 61 (33.5\%) patients between 1 month and 1 year (mean 5.5 months), 46 (25.5\%) between 1 and 5 years (mean 2 years 7 months) and 21 (11.5\%) between 5 and 12 years (mean 8 years 3 months) ${ }^{9}$. Another study conducted by Priti et al., and described that out of 20 children 4 were less than one month, 4 were between 1 month to 1 year and other 12 were between 1 and 5.5 years ${ }^{10}$.

In our study more than two third of subjects had weak urinary stream $(80.0 \%)$. Rest had normal urinary stream (20.0\%). Dribbling of urine was present among $76.7 \%$. Other had no dribbling of urine (23.3\%). More than two third of the study subjects had straining at micturition $(73.3 \%)$ and $26.7 \%$ had no such symptom. Half of the subjects had urinary tract infection $(50.0 \%)$. Another study done by Priti et al in 2004 enrolled 20 children having PUVs. Among the study subjects $4(20 \%)$ were neonate age group and had poor urine output, dribbling of urine with palpable bladder with poor feeding. Of the infant age group 3 were diagnosed following recurrent UTIs and one for poor urine stream. Of the remaining 12 children six presented with recurrent UTI, one with abdominal distension and dribbling and 5 with straining at micturition and narrow urine stream ${ }^{10}$.

Most of the study subjects had no congenital anomaly $(96.7 \%)$. Only $3.3 \%$ had congenital anomaly. After clinical examination only $6.7 \%$ kidneys were found ballotable. Rest was not ballotable on palpation. In more than two third of the cases bladder was found palpable (73.3\%). Rest was not palpable (26.7\%). Phimosis was present in $20.0 \%$ cases. Rest had no phimosis $(80.0 \%)$. Average serum creatinine level was found gradually decreased in subsequent follow up in 
comparison with the previous one. This difference of creatinine level was found statistically significant in ttest $(p<0.01)$. Average BUN also decreased which was found statistically significant $(p<0.05)$. In another study done by Narasimhan et al., pointed that primary valve fulguration was performed in 41 patients, the median follow up was 3.5years (range 1.5-15years) 11. The preoperative and postoperative serum creatinine at the end of 1 year did not differ but in our study the creatinine level was decreased subsequent follow up which was not similar findings to Narasimhan's et al., study. A study by Priti et al., the blood urea and serum creatinine levels, which were raised in $50 \%$ of the patients at presentation, came down to normal by 6 months in all the cases after primary fulguration. The mean creatinine level was $1.32 \pm 0.9 \mathrm{mg} \%$ (range $0.5-4.5 \mathrm{mg} \%$ ). These values subsequently came down to $0.81 \pm 0.27 \mathrm{mg} \%$ and 0.6 $\pm 0.25 \mathrm{mg} \%$ for the serum creatinine at the 3 and 6 months follow up which was similar findings to our study.

On admission Hydronephrosis of different grades was found in $95.7 \%$ cases. Grade 0 hydronephrosis were found in $3.3 \%$ cases which became $20 \%$ after 3 months. Grade III hydronephrosis were found in $16.7 \%$ cases on admission which decreased after 3 months $(6.7 \%)$. Hydronephrosis was present in all the patients at presentation and was bilateral in $90 \%$. It decreased significantly during the follow-up period, though its complete disappearance was seen only in one case 10 .

Reflux is the major cause of postnatal damage in PUVs and persistence reflux is associated with bad outcome 12. A study done by Johnston and Kulatilake showed that resolution of reflux in a significant number of patients following fulguration. Johnston and Kulatilake also reported VUR in $26 \%$ of the renal units, $56 \%$ being unilateral. Reflux subsided in $40 \%$ of the patients after fulguration. The time taken for resolution was as short as 2 weeks, though maximum period remain unknown 13. A 66\% VUR was reported by Johnston et al., (1979), 52\% being unilateral. Reflux ceased in $55 \%$ in 2 weeks to 13 months 14 . A study conducted by Priti et al., and showed $60 \%$ children having VUR at presentation, with $41.7 \%$ being unilateral. Reflux was present in $47.5 \%$ initially, subsiding in $31.55 \%$ by 3 months and in $78.9 \%$ by 6 months after fulguration and the remaining 3 units showed reduction in the grade of reflux. In our study VUR was present $63.3 \%$. On admission non-VUR was found in $60 \%$ cases in right side and $50 \%$ cases in left side. On the third follow-up that is after 3 months it became $73.3 \%$ in right side and $63.3 \%$ in left side. The rate of disappearance of reflux in our study is therefore much higher than the rate described earlier. In our study we concluded that positive correlation was found in Pearson correlation test about the changes of reflux grades before and after fulguration which was significant at the level of $0.01(p<0.001)$. This correlation was significant in both left and right kidneys.

In our study positive correlation was found in Pearson correlation test about the changes of GFR before and after fulguration which was significant at the level of 0.01 ( $p<0.001$ ). Improvement in glomerular filtration rate (GFR) was noted in the children at each followup and was found to be statistically significant $(p<0.01)$, described by Priti et al., (2007).

Children can suffer from renal damage due to recurrent urinary tract infection (UTI) not promptly diagnosed or subsequently evaluated. The highest incidence of underlying urinary tract abnormalities, such as vesicoureteral reflux, also occurs in this young age group. By promptly recognizing and appropriately treating the UTI, the physician minimizes the risk of injury to the kidneys. On admission $46.7 \%$ patients had found bacterial growth in culture of urine which became $10.0 \%$ after 1 month and after 3 months it was $13.3 \%$ which due to non compliance of patients. On admission $53.3 \%$ patients had urinary tract infection based on Urine R/M/E which became 16.7\% after 1 month. After 3 months it was 13.3\%.

Studies in patients with valves and bilateral reflux have demonstrated an inverse relationship between filling detrusor pressure and GFR 15. Although we could not drive any clear cut correlation between rise in GFR and the resolution of reflux, we feel that they are both secondary to the reduction in back pressure following adequate fulguration. Although our study group was small, we did not come across any patient with persistent bladder dysfunction. This series includes only those patients who underwent fulguration. However we feel that adequate fulguration is the key to improvement of reflux and renal function in majority of cases.

\section{Conclusion:}

In this study, VUR disappeared in some cases and decreased in majority of the cases by three months 
after adequate restoration of urethral patency. Renal function came to normal range in two thirds of the cases. To clarify the improvement of VUR after primary fulguration, more follow up period is required.

\section{References:}

1. Gatti JM, Kirsch AJ. Posterior urethral valves: pre- and postnatal management. Curr Urol Rep 2001;2:138-45.

2. Gonzales ET. Posterior urethral valves and other urethral anomalies. In: Walsh PC, et al (eds): Campbell's Urology.Philadelphia, WB Saunders, 2002; 2207-2330.

3. Young $\mathrm{H}$, Frontz WA, Baldwin JC. Congenital obstruction of posterior urethra. J Urol 1919; 3:289.

4. Stephens FD. Congenital Malformations of the Urinary tract. New York: Praeger, 1983; 577.

5. Field PL, Stephens FD. Congenital urethral membranes causing urethral obstruction. J Urol 1974;41:240-2.

6. Lebowitz RL, Olbing H, Parkklainen KV, Smellie JM, Tamminen-Mobius TE. International system of radiographic grading of vesicoureteric reflux.International refluxstudy in children. Pediatr Radiol 1985;15:105-109.

7. Majd M. Nuclear medicine in pediatric urology. In:Kelalis PP, King LR, Belman AB(eds) Clinical pediatric urology.Saunders, Philadelpia 1992;117-165.
8. Gates GF. Split renal function testing using Tc99m DTPA. A rapid technique for determining differential glomeruler function. Clin Nucl Med 1983;8:400-407.

9. Menon P, Rao K.L.N, Vijaymahantesh S. Kanojia R.P,Samujh R,Batra Y.K, et al., Posterior urethral valves: Morphological normalization of posterior urethra after fulguration is a significant factor in prognosis. J Indian Assoc Pediatr sug 2010; 15 (3):80-86.

10. Priti K, Rao K.L.N, Menon P, Singh N, Mittal B.R.,Bhattacharya A, Mitra S.K. Posterior urethral valves: incidence and progress of vesicoureteric reflux after primary fulguration. Pediatr Surg Int 2004;20:136-139.

11. Narasimhan KL, Kaur B, Chowdhury SK, Bhalla AK. Does mode of treatment affect the outcome of neonatal Posterior urethral valves? J Urol 2004; 171:2423-6.

12. Parkhouse HF, Barrate TM, Dilon MJ, Duffy PG, Fay J, Ransley PG, et al., Long term outcome of boys with posterior urethral valves. $\mathrm{Br} \mathrm{J}$ Urol 1988;62:59-62.

13. Johnston $\mathrm{JH}$, Kulatilake $\mathrm{AE}$. The sequelae of posterior urethral valves. Br J Urol 1971; 43:74348.

14. Johnston $\mathrm{JH}$. Vesicoureteric reflux with urethral valves. Br J Urol 1979;51:100-104.

15. Parkhouse HF, Woodhouse CR. Long-term status of patients with posterior urethral valves. Urol Clin North Am 1990;17:373-378. 